\title{
Reaction pathways in the solid state synthesis of multiferroic $\mathrm{BiFeO}_{3}$
}

\author{
M.S. Bernardo, T. Jardiel, M. Peiteado*, A.C. Caballero, M. Villegas \\ Department of Electroceramics, Instituto de Cerámica y Vidrio, CSIC, C/Kelsen 5, 28049 Madrid, Spain
}

\begin{abstract}
The obtaining of multiferroic $\mathrm{BiFeO}_{3}$ as a pure single-phase product is particularly complex since the formation of secondary phases seems to be unavoidable. The process by which these secondary impurities are formed is studied by analyzing the diffusion and solid state reactivity of the $\mathrm{Bi}_{2} \mathrm{O}_{3}-\mathrm{Fe}_{2} \mathrm{O}_{3}$ system. Experimental evidence is reported which indicates that the progressive diffusion of $\mathrm{Bi}^{3+}$ ions into the $\mathrm{Fe}_{2} \mathrm{O}_{3}$ particles governs the solid state synthesis of the perovskite $\mathrm{BiFeO}_{3}$ phase. However a competition is established between the diffusion process which tends to complete the formation of $\mathrm{BiFeO}_{3}$, and the crystallization of stable $\mathrm{Bi}_{2} \mathrm{Fe}_{4} \mathrm{O}_{9}$ mullite crystals, which tend to block that formation reaction.
\end{abstract}

Keywords: Ferrites; Perovskites; Powders-solid state reaction; Diffusion couples; Microstructure

\section{Introduction}

Multiferroic materials present simultaneously ferroelectric, ferromagnetic and/or ferroelastic ordering. ${ }^{1}$ These kind of materials have received a great interest in the last years due to their potential applications in data storage systems, sensors, filters, attenuators and/or spintronics devices. ${ }^{2}$ So far perovskite $\mathrm{BiFeO}_{3}$ is one of the most promising multiferroic materials. It shows anti-ferromagnetic order up to $370^{\circ} \mathrm{C}$ and ferroelectric order up to $825^{\circ} \mathrm{C} .4,4$ Also an enhanced magnetization and a large spontaneous polarization of $50-60 \mu \mathrm{C} / \mathrm{cm}^{2}$ has been reported for $\mathrm{BiFeO}_{3}$ epitaxially grown thin films. ${ }^{5,6}$ Bulk $\mathrm{BiFeO}_{3}$ on the contrary shows a spontaneous polarization value significantly smaller (either in single crystal or in polycrystalline ceramic), but it is not clear yet whether this results from the material intrinsic properties or essentially comes from limitations imposed by imperfections in the bulk, like for example the presence of secondary phases. ${ }^{3}$ Actually the synthesis and properties of $\mathrm{BiFeO}_{3}$ have been widely studied in the literature but up to date the obtaining of the bismuth ferrite as a pure singlephase product still represents a major challenge. One of the first works date back to the sixties when Achenbach et al. already reported that during the synthesis of stoichiometric $\mathrm{BiFeO}_{3}$, the kinetics of phase formation in the $\mathrm{Bi}_{2} \mathrm{O}_{3}-\mathrm{Fe}_{2} \mathrm{O}_{3}$ system easily results in the appearance of the sillenite-type $\mathrm{Bi}_{25} \mathrm{FeO}_{39}$ and the mullite-type $\mathrm{Bi}_{2} \mathrm{Fe}_{4} \mathrm{O}_{9}$ impurity phases. ${ }^{7}$ These secondary

\footnotetext{
* Corresponding author. Tel.: +34917355840 ; fax: +34917355843.

E-mail address: mpeiteado@icv.csic.es (M. Peiteado).
}

by-products have been interpreted as intermediates in the formation of the ferrite, ${ }^{8,9}$ but the fact is that their elimination through a simple mixed-oxides solid state reaction route has proven extremely difficult if not impossible. ${ }^{10-12}$ Many alternative strategies have been (are being) attempted to prepare pure $\mathrm{BiFeO}_{3}$, from a rapid liquid-phase sintering, ${ }^{13,14}$ a microwave or spark-plasma assisted sintering, ${ }^{15,16}$ or even a mechanochemical high energy milling processing, ${ }^{17}$ to different wet chemical methods ${ }^{18-24}$; but even in those that have succeed, the precise reaction mechanisms have not been identified yet. Why the secondary phases are usually present in the system is source of discussion in the literature: the presence of trace impurities, ${ }^{25}$ the formation of non-stoichiometric solid solutions ${ }^{26}$ and/or a certain degree of thermodynamic metastability, ${ }^{9}$ have been proposed to explain such an anomalous situation for a presumed $\mathrm{Bi}_{2} \mathrm{O}_{3}-\mathrm{Fe}_{2} \mathrm{O}_{3}$ binary system. However, as mentioned a clear description of the possible reaction pathways is still missing, being this a key point to understand when, in the process, the secondary phases are formed. Accordingly in the present contribution different experiments are conducted to more clearly identify the solid state reactivity of the system. Special emphasis is made on the diffusion behavior of the involved structures and in view of the obtained results a plausible mechanism is proposed.

\section{Experimental procedure}

The obtaining of single-phase $\mathrm{BiFeO}_{3}$ was initially attempted using a conventional mixed-oxides ceramic processing route. $\mathrm{Bi}_{2} \mathrm{O}_{3}$ and $\mathrm{Fe}_{2} \mathrm{O}_{3}$ analytical reagent-grade chemicals were pur- 
chased from Sigma-Aldrich and used in received form without further purification. In a typical procedure the stoichiometric mixture of both oxides was subjected to a $2 \mathrm{~h}$ milling step on a Teflon-lined attrition mill, with YSZ balls and ethanol as liquid medium. The dried mixture was sieved under a $100 \mu \mathrm{m}$ mesh and then powder samples and uniaxially pressed pellets (100 MPa) were placed on platinum crucibles for the thermal treatments. Initially samples were fired at temperatures ranging from 600 to $1000^{\circ} \mathrm{C}$ with soaking times of $2-48 \mathrm{~h}$; heating and cooling rates of $3{ }^{\circ} \mathrm{C} / \mathrm{min}$ were programmed in these experiments. But in addition fast firing treatments were tested in which powder and pelletized samples were cautiously introduced on a pre-heated furnace, dwelled for a certain time and rapidly quenched in liquid nitrogen. The same temperatures and soaking times used for the slowly heated samples were applied to the fast firing experiments. All treatments were conducted in air atmosphere.

The synthesis of $\mathrm{BiFeO}_{3}$ nominal composition was also attempted by a room-temperature co-precipitation technique. Again reagent-grade raw materials from Sigma-Aldrich were used. The stoichiometric amounts of $\mathrm{Bi}\left(\mathrm{NO}_{3}\right)_{3} \cdot 9 \mathrm{H}_{2} \mathrm{O}$ and $\mathrm{Fe}\left(\mathrm{NO}_{3}\right)_{3} \cdot 5 \mathrm{H}_{2} \mathrm{O}$ were dissolved in $200 \mathrm{ml}$ of $\mathrm{HNO}_{3} 1 \mathrm{M}$ and the obtained solution was added drop wise into a 11 aqueous solution of $\mathrm{NH}_{4} \mathrm{OH}$ ( $50 \mathrm{vol}$.\%) under vigorous stirring. To ensure the simultaneous precipitation of both bismuth and iron ions the final $\mathrm{pH}$ of the solution was kept at $9.4 .^{27}$ The resulting precipitate was retrieved from the solution by filtration, washed several times with ethanol and distilled water and finally calcined at $300^{\circ} \mathrm{C}$ to cleanly decompose it into the corresponding oxide. The calcined powder was attrition milled for $2 \mathrm{~h}$ and the same thermal treatments previously applied to the mixed-oxides samples (slow heating and fast firing) were applied to powder and pellet samples.

Eventually the solid-state reactivity of the $\mathrm{Bi}_{2} \mathrm{O}_{3}-\mathrm{Fe}_{2} \mathrm{O}_{3}$ system was analyzed using the diffusion couples technique. The preparation of the couples is described elsewhere ${ }^{28}$ : a $20 \mathrm{~mm}$ diameter base of $\mathrm{Fe}_{2} \mathrm{O}_{3}$ powder was first pressed at $50 \mathrm{MPa}$; subsequently a $6 \mathrm{~mm}$ diameter pellet of $\mathrm{Bi}_{2} \mathrm{O}_{3}$ powder, previously pressed at $200 \mathrm{MPa}$, was placed over this base, and then the dye was filled with more $\mathrm{Fe}_{2} \mathrm{O}_{3}$ powder until the bismuth oxide pellet was plenty covered. A thin platinum film was placed in between the pellets to more clearly identify the couple interface. The whole ensemble was pressed at a pressure of $250 \mathrm{MPa}$. The diffusion couples thus obtained were heated at temperatures ranging from 600 to $750{ }^{\circ} \mathrm{C}$ with a $20 \mathrm{~h}$ soaking time followed by a quench in air; it is important to notice that at theses temperature the interaction with the Pt indicator and the bismuth oxide is negligible. Three samples were fired at each temperature.

The thermal evolution of the $\mathrm{Bi}_{2} \mathrm{O}_{3}-\mathrm{Fe}_{2} \mathrm{O}_{3}$ stoichiometric mixture was followed by differential thermal analysis and thermogravimetry (DTA-TG) on a Netzsch STA 449C instrument in air atmosphere at a heating rate of $3^{\circ} \mathrm{C} / \mathrm{min}$. Characterization of the prepared powders and pellets was carried out by means of powder X-ray diffraction (XRD) and scanning electron microscopy (SEM). For the XRD profile analyses, step-scanned patterns were collected between 15 and $65^{\circ}$ using $\mathrm{CuK}_{\alpha}$ radiation on a Bruker AXS D8 Advance diffractometer with a

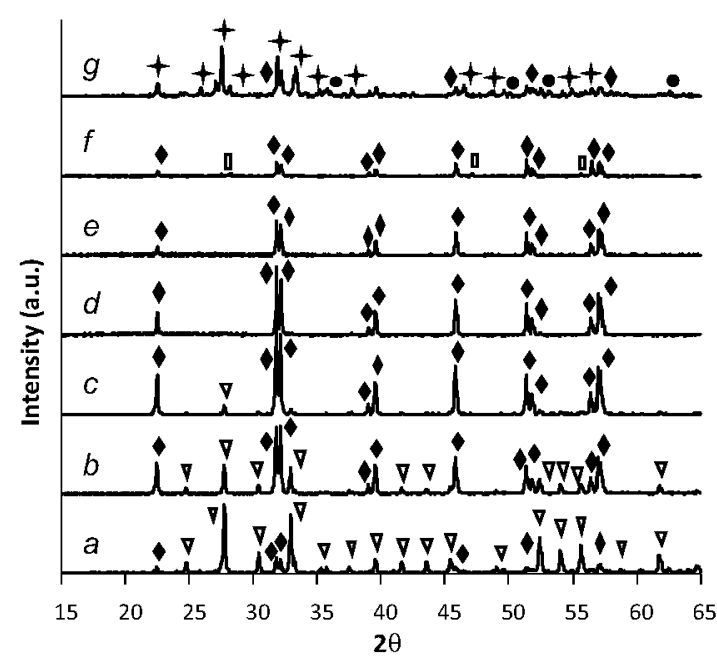

Fig. 1. X-ray diffractograms of the powders obtained by the mixed-oxides route and calcined at: (a) $600^{\circ} \mathrm{C}$, (b) $650^{\circ} \mathrm{C}$, (c) $700^{\circ} \mathrm{C}$, (d) $750^{\circ} \mathrm{C}$, (e) $800^{\circ} \mathrm{C}$, (f) $900^{\circ} \mathrm{C}$ and $(\mathrm{g}) 1000^{\circ} \mathrm{C}$. $(\bullet) \mathrm{BiFeO}_{3},(\nabla) \mathrm{Bi}_{25} \mathrm{FeO}_{39},(\square) \mathrm{Bi}_{2} \mathrm{Fe}_{4} \mathrm{O}_{9},(+) \mathrm{Bi}_{2} \mathrm{O}_{3}$ and $\left(\mathrm{Fe}_{2} \mathrm{O}_{3}\right.$.

LynxEye 1-D linear detector and a secondary monochromator. For the SEM investigations, a scanning electron microscope (Model TM-1000 Hitachi) was used for preliminary microstructural analysis. For a more detailed characterization a cold field emission scanning electron microscope (FE-SEM, Model S-4700 Hitachi) equipped with energy dispersive X-ray microanalysis (EDX) was also used. Thermal etching was applied to reveal the most significant microstructural features of the ceramic samples. In the particular case of the diffusion couples samples, the couples were carefully fractured and separated, but polishing was not used to prevent contamination in between the confronted pellets.

\section{Results and discussion}

The evolution of the $\mathrm{BiFeO}_{3}$ stoichiometric composition was initially studied by ex situ XRD measurements conducted on isothermally treated samples of the $\mathrm{Bi}_{2} \mathrm{O}_{3}-\mathrm{Fe}_{2} \mathrm{O}_{3}$ mixture prepared by the mixed-oxides solid-state synthesis method. Fig. 1 depicts the diffractograms corresponding to calcination experiments for $2 \mathrm{~h}$ at different temperatures. First peaks of the perovskite $\mathrm{BiFeO}_{3}$ phase (JCPDS file no 72-2112) can be observed already at $600^{\circ} \mathrm{C}$, together with intense signals of the sillenite $\mathrm{Bi}_{25} \mathrm{FeO}_{39}$ compound, visibly the major phase at this low temperature (JCPDS file no 77-0865). Increasing the temperature decreases the amount of the sillenite product and apparently the $\mathrm{BiFeO}_{3}$ is obtained as a pure single phase at temperatures between 750 and $800^{\circ} \mathrm{C}$. Above this temperature, in particular after $2 \mathrm{~h}$ at $900^{\circ} \mathrm{C}$, the $\mathrm{BiFeO}_{3}$ seems to have initiated its decomposition and trace amounts of the $\mathrm{Bi}_{2} \mathrm{Fe}_{4} \mathrm{O}_{9}$ mullite-type phase (JCPDS file no 25-0090) can be observed in the corresponding diffractogram, together with small signals of a Bi-rich phase (probably sillenite coming from an amorphous liquid phase $\mathrm{e}^{29}$ ). Finally at $1000^{\circ} \mathrm{C}$, well above the peritectic decomposition temperature, peaks of the $\mathrm{Fe}_{2} \mathrm{O}_{3}$ and $\mathrm{Bi}_{2} \mathrm{O}_{3}$ compounds (JCPDS file nos 79-0007 and 71-0465, respec- 


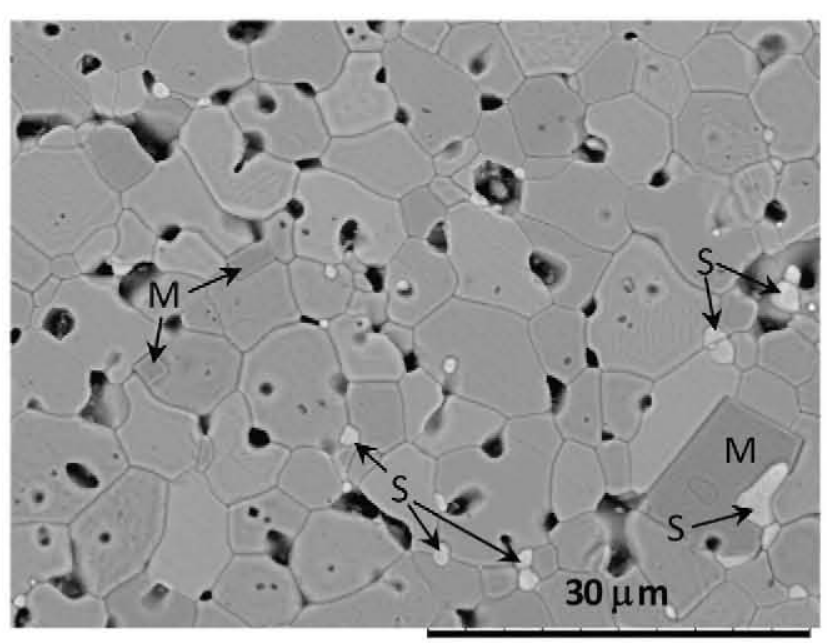

Fig. 2. SEM micrograph of the sample obtained by the mixed-oxides and calcined at $750^{\circ} \mathrm{C} / 2 \mathrm{~h}$. To reveal the microstructure sample was thermally treated at $675^{\circ} \mathrm{C}$ for $10 \mathrm{~min}$. Grains of the mullite-type $\mathrm{Bi}_{2} \mathrm{Fe}_{4} \mathrm{O}_{9}$ and sillenite-type $\mathrm{Bi}_{25} \mathrm{FeO}_{39}$ secondary phases are marked in the image by $\mathrm{M}$ and $\mathrm{S}$, respectively. Unmarked light-grey grains correspond to perovskite $\mathrm{BiFeO}_{3}$.

tively) and some remaining of the $\mathrm{BiFeO}_{3}$ phase can be barely identified.

SEM micrograph in Fig. 2 shows the thermally etched surface of the sample calcined at $750^{\circ} \mathrm{C}$ for $2 \mathrm{~h}$ (sample was calcined as a pellet and the thermal etch was conducted at $675^{\circ} \mathrm{C}$ for $10 \mathrm{~min})$. Well-faceted dark grains and irregular whitish areas can be detected immersed in a matrix of light grey grains. The corresponding EDX analyses revealed a composition close to $\mathrm{BiFeO}_{3}$ for the grey matrix, a composition close to sillenite $\mathrm{Bi}_{12.5} \mathrm{Fe}_{0.5} \mathrm{O}_{19.5}$ for the white regions and a composition close to $\mathrm{Bi}_{2} \mathrm{Fe}_{4} \mathrm{O}_{9}$, i.e. mullite, for the dark grains. This indicates that in spite of the apparently single-phase X-ray diffractograms, the $\mathrm{BiFeO}_{3}$ phase was not synthesized as a pure product from these mixed-oxides experiments. Furthermore, repeated grinding-firing and/or prolonged annealing times were also tried but, as happened before to some other authors, ${ }^{10,25}$ no significant changes in the phase distributions and fractions were observed. Therefore it seems that once the secondary phases are formed they are tricky to remove and attempts should be made to circumvent their formation. In this sense one presumed possibility is to go straightly to the temperatures at which the 1:1 perovskite phase is stable with regards to the other two phases of the systems; according to previous reports by Selbach et al. this may be achieved by rapid heating and fast cooling the $\mathrm{Bi}_{2} \mathrm{O}_{3}-\mathrm{Fe}_{2} \mathrm{O}_{3}$ mixture at $T>767^{\circ} \mathrm{C}$. $^{9,30}$ Another plausible option would involve the increase in the system reactivity: this can be done by applying a more reactive wet chemical synthesis method, something recurrently used in the literature and that also reduces the probability of impurity contamination. Accordingly, we designed some fast firing and co-precipitation experiments whose major features are described in Section 2, and with the obtained powders we ran the corresponding calcination treatments. Fig. 3 shows the X-ray diffractograms of some representative of these calcinations and as observed a similar scenario to that of the solid-state synthesized samples is unavoidably achieved: the amount of secondary phases slightly
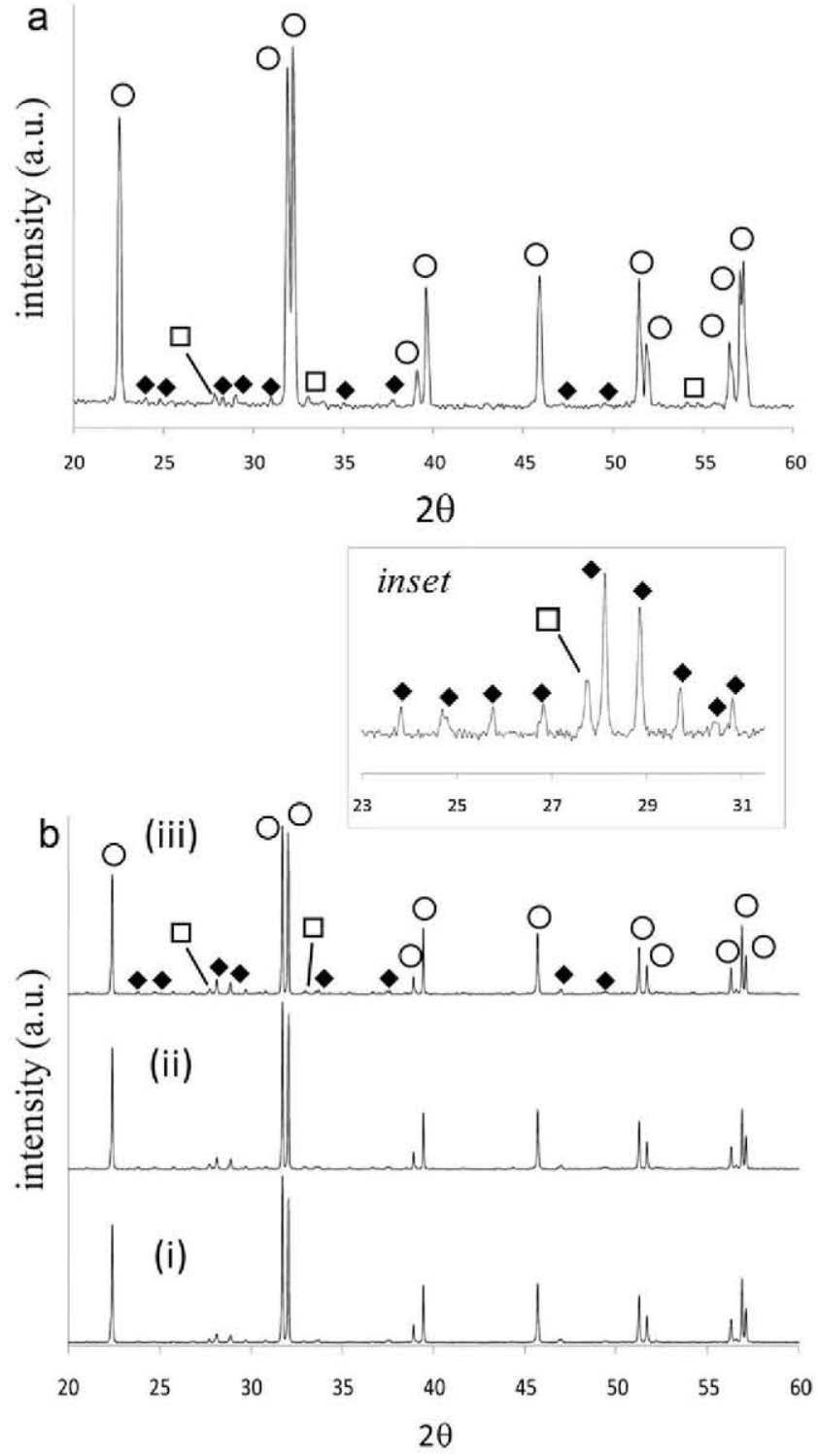

Fig. 3. X-ray diffractograms of (a) sample obtained by the mixed-oxides route and fast fired at $775^{\circ} \mathrm{C} / 48 \mathrm{~h}$ and (b) samples obtained by co-precipitation and calcined at (i) $650^{\circ} \mathrm{C}$, (ii) $700^{\circ} \mathrm{C}$ and (iii) $750^{\circ} \mathrm{C}$. (O) $\mathrm{BiFeO}_{3}$, ( $\square$ ) $\mathrm{Bi}_{25} \mathrm{FeO}_{39}$ and $(\rightarrow) \mathrm{Bi}_{2} \mathrm{Fe}_{4} \mathrm{O}_{9}$. A magnified vision of the peaks between $2 \theta=23$ and 31 is shown in the inset.

fluctuates with the preparation conditions and the heat treatments but again we were unable to obtain the pure $\mathrm{BiFeO}_{3}$ single phase. Moreover, in the co-precipitated samples the amount of the secondary $\mathrm{Bi}_{2} \mathrm{Fe}_{4} \mathrm{O}_{9}$ mullite phase is visibly higher than in the mixed-oxides experiments (notice it can be detected already by XRD).

This last result was in some way unexpected; the implicit increase in the system reactivity induced by the chemical synthesis should promote the complete formation of the stoichiometric compound, $\mathrm{BiFeO}_{3}$, but instead it favors the crystallization of the secondary products. Somehow this means that the formation reaction of $\mathrm{BiFeO}_{3}$ is not completed, it is blocked at some particular point, and actually any change in the energy conditions indeed favors the multiphase configuration. To clarify this situation we subsequently focused our research on the analy- 


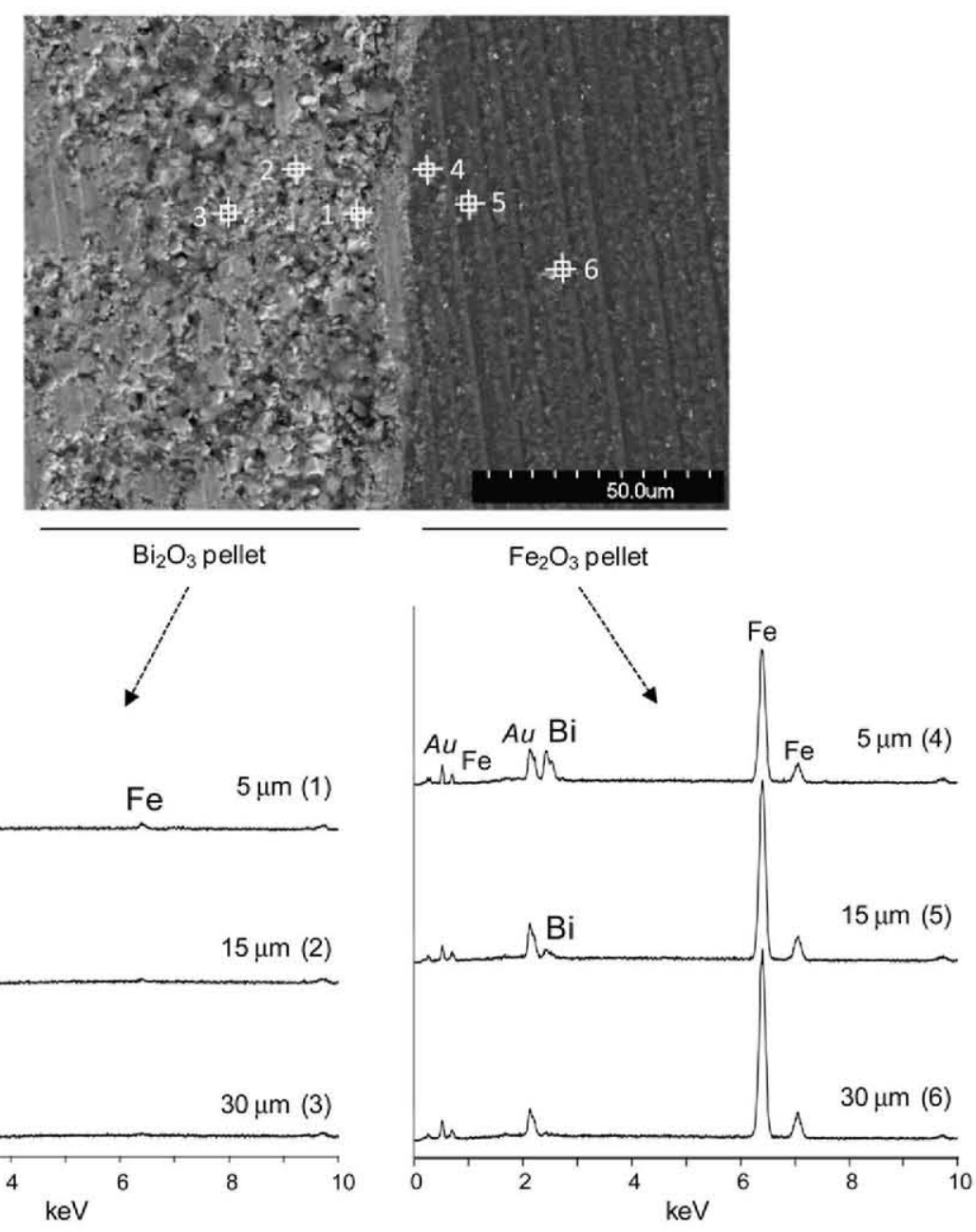

Fig. 4. SEM and EDX analyses of the $\mathrm{Bi}_{2} \mathrm{O}_{3}-\mathrm{Fe}_{2} \mathrm{O}_{3}$ diffusion couple treated at $650^{\circ} \mathrm{C}$ for $2 \mathrm{~h}$ and air quenched.

sis of the solid state reactivity and the diffusion behavior of the $\mathrm{Bi}_{2} \mathrm{O}_{3}-\mathrm{Fe}_{2} \mathrm{O}_{3}$ raw system, something that was faced using the well-known technique of the diffusion couples. This method has proved quite successful for studying the solid state interaction between different binary, ternary and multiphase ceramic systems. ${ }^{31-33}$ On use it, we take into account that when reactants are not in direct contact the reaction is entirely dependent on the diffusion of reactants. ${ }^{34}$ Couples of the binary mixture were prepared as specified in Section 2 and Fig. 4 summarizes the results obtained for the pair treated at $650^{\circ} \mathrm{C}$ for $20 \mathrm{~h}$ and air quenched (similar trends were observed for the other temperatures tested). As illustrated in the SEM micrograph, the two corresponding $\mathrm{Bi}_{2} \mathrm{O}_{3}$ and $\mathrm{Fe}_{2} \mathrm{O}_{3}$ pellets of the couple are separated by an interface layer of different colorations with an average width of approximately $5 \mu \mathrm{m}$. EDX of this area revealed a major amount of $\mathrm{Bi}$ and the corresponding $\mathrm{X}$-ray diffractogram pointed out towards the presence of the three phases: perovskite, mullite and sillenite. However the most revealing results were obtained when analyzing the diffusion profiles of $\mathrm{Bi}$ and $\mathrm{Fe}$ species on the respective $\mathrm{Fe}_{2} \mathrm{O}_{3}$ and $\mathrm{Bi}_{2} \mathrm{O}_{3}$ pellets. As observed in the EDX spectra, whereas a significant amount of Bi penetrates several microns inside the $\mathrm{Fe}_{2} \mathrm{O}_{3}$ pellet (up to $15 \mu \mathrm{m}$ away from the interface layer), the detection of $\mathrm{Fe}$ is rather symbolic after just $5 \mu \mathrm{m}$ inside the $\mathrm{Bi}_{2} \mathrm{O}_{3}$ pellet. Thus we can infer that the diffusion of bismuth ions activates before the diffusion of iron species, which in other words means that the solid state interaction, and hence the formation of the $\mathrm{BiFeO}_{3}$, is controlled by the diffusion of bismuth through the $\mathrm{Fe}_{2} \mathrm{O}_{3}$ grains.

Previous works with other systems have shown that in addition to the ion size and the charge mismatch of the diffusing species, the crystal structure of the involved compounds can be determinant to explain the diffusion behavior of a particular system..$^{28,33,35}$ Similarly we suggest that the different crystal structures of $\mathrm{Bi}_{2} \mathrm{O}_{3}$ (polymeric-like layer structure) ${ }^{36}$ and $\mathrm{Fe}_{2} \mathrm{O}_{3}$ (highly compacted corundum type) ${ }^{36}$ are affecting the observed diffusion patterns in this particular system.

With this in mind we performed a new detailed analysis of the microstructure of some selected samples, this time using a Field Emission Scanning Electron Microscope. In particular we focused on a sample that we already characterized on the SEM microscope, the sample treated at $750^{\circ} \mathrm{C}$ for $2 \mathrm{~h}$ and thermally etched at $675^{\circ} \mathrm{C}$ (Fig. 2). The results of this new characterization are presented in Fig. 5. The FE-SEM image in Fig. 5a shows a relatively big grey grain $(5-6 \mu \mathrm{m}$ in size $)$ with a white brilliant remaining of a secondary phase at the boundary. According to the above described analyses the grey grain will stand for the per- 

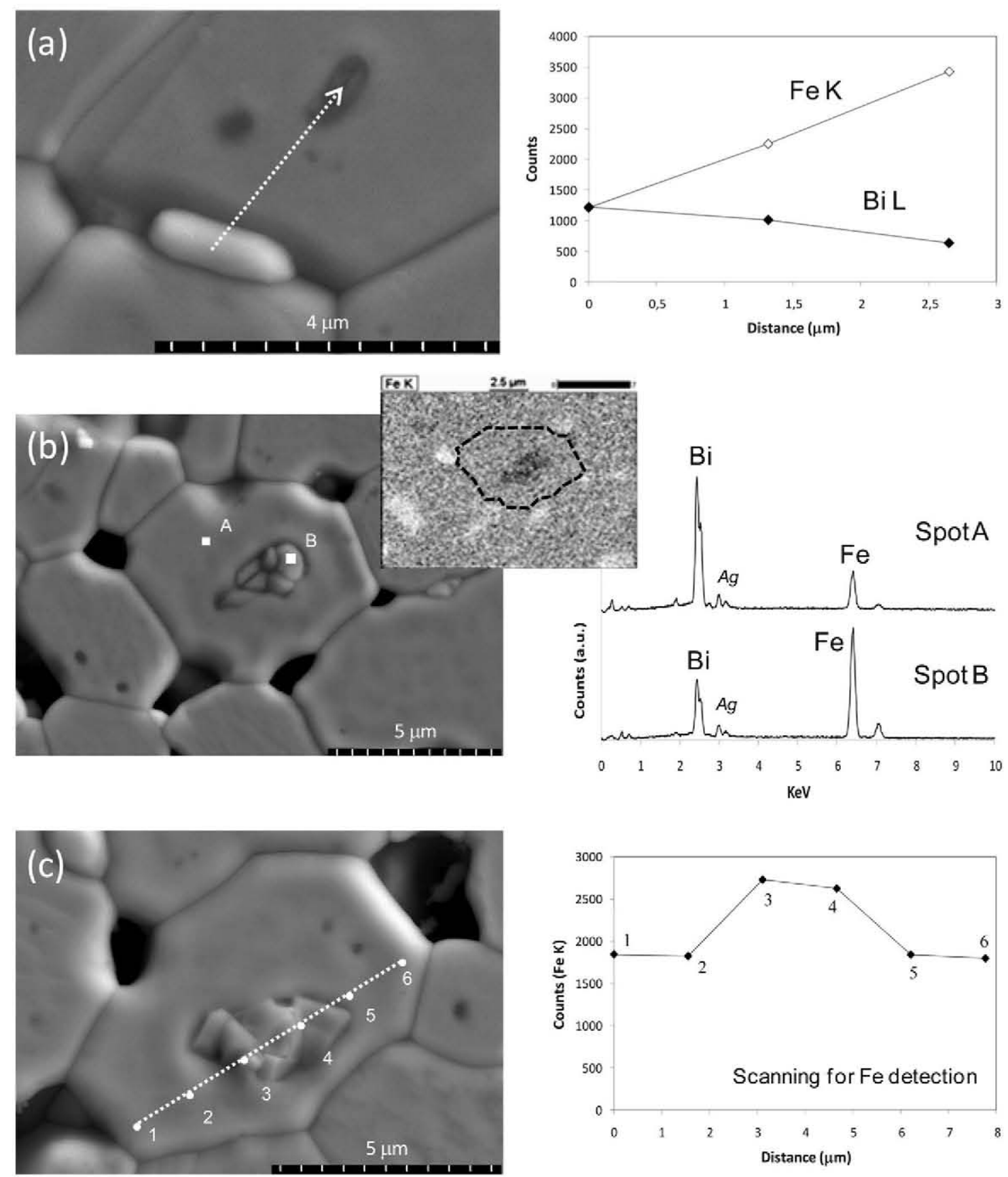

Fig. 5. FE-SEM and EDX analyses of the sample obtained by the mixed-oxides route at $750^{\circ} \mathrm{C} / 2 \mathrm{~h}$ and thermally treated at $675^{\circ} \mathrm{C}$ for $10 \mathrm{~min}$.

ovskite ferrite while the white grain must be ascribed to sillenite. The corresponding EDX spectra although qualitative confirmed these compositions; moreover the sillenite is expected to form a liquid at temperatures close to $750-800^{\circ} \mathrm{C}^{29}$ and the fact is that looking carefully all along the grain boundary, it could be perceived the track through which this white phase could have retracted during the thermal treatment. But in addition the FESEM micrograph in Fig. 5a also evidences the presence of two sizeable blackened spots in the interior of the grey grain. An EDX scan was performed from the white grain of sillenite in the boundary to one of the black spots in the middle of the grey grain (marked by an arrow in the image); as depicted in the cor- responding graph, the Bi content gradually decreases whereas the Fe content significantly increases as the middle of the grain is approached. In view of that, the black spots will correspond to an iron-rich compound, either mullite or the starting iron oxide, which will be somehow waiting for the arrival of more diffusing bismuth ions to proceed with the reaction. The two micrographs in Fig. $5 b$ and $5 c$ even make more evident this picture. Both images now show the presence of a small group of submicronic grains inside the ferrite grey grains. Next to the micrographs, the corresponding EDX analyses (single spectra, scans and mappings) all indicate that these internal grains have higher iron contents than the grains in which they are imbued, and accord- 

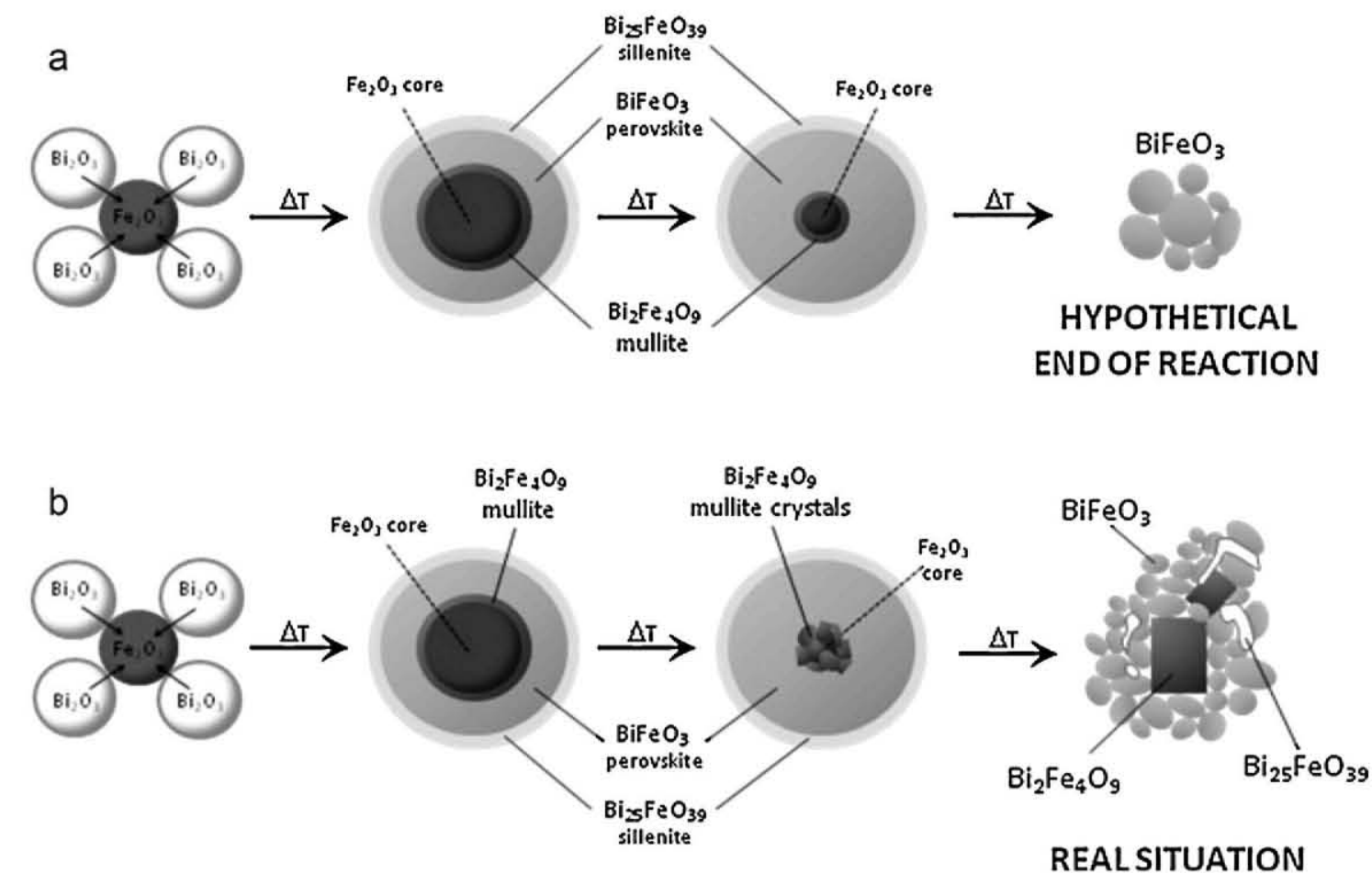

Fig. 6. Schematic diagram of the reaction paths in the solid state synthesis of $\mathrm{BiFeO}_{3}$. (a) Hypothetical end of reaction and (b) experimental situation.

ing to their faceted appearance (especially of those grains in Fig. $5 \mathrm{c}$ ) it is likely that they correspond to already crystallized grains of the mullite phase. Consequently in this case the reaction would be already blocked and the only progress that could be expected is the growing of the mullite particles to form those well-faceted rectangular dark grains of mullite seen in Fig. 2.

According to these results we can suggest a plausible mechanism for the reaction stages during the solid state synthesis of $\mathrm{BiFeO}_{3}$. A mechanism which schematized in Fig. 6 can be described as follows: as the reaction proceeds, the penetration profile of the $\mathrm{Bi}$ ions into the $\mathrm{Fe}_{2} \mathrm{O}_{3}$ particles will lead to the formation of different compounds. Initially, and comparable to a what is known as a core-shell configuration, ${ }^{37-40}$ the $25: 1$ $(\mathrm{Bi}: \mathrm{Fe})$ sillenite phase will be formed in the outer surface and the $1: 1 \mathrm{BiFeO}_{3}$ perovskite phase will develop as we move inside the structure. But also nuclei of the $1: 2 \mathrm{Bi}_{2} \mathrm{Fe}_{4} \mathrm{O}_{9}$ phase would form deeper inside, constituting the diffusion/reaction front towards the iron oxide core. As the temperature increases diffusion will be favored and more perovskite may be formed in spite of the iron-rich nucleus. In a hypothetical end of reaction the mullite front should entirely decompose to complete the reaction and just grains of the stoichiometric $\mathrm{BiFeO}_{3}$ phase should be expected (Fig. 6a). However the real situation is far from that and as described some remaining of the sillenite and mullite phases are always present in the samples. It happens that the increase in temperature, which certainly leads to an enhanced diffusion of $\mathrm{Bi}$ ions and consequently accelerates the reaction process, also promotes the crystallization of the mentioned $\mathrm{Bi}_{2} \mathrm{Fe}_{4} \mathrm{O}_{9}$ nuclei. Once crystallized the mullite primary particles are exceptionally stable (the well-faceted rectangular crystals observed in the micrographs may account for that high stability) and con- sequently the reaction is stopped in a situation in which the $\mathrm{BiFeO}_{3}$ coexists with small amounts of the other two phases (Fig. 6b). A competition is thus established between two different processes: the diffusion of the $\mathrm{Bi}$ ions throughout the iron oxide particles to complete the formation of $\mathrm{BiFeO}_{3}$ on the one hand, and the crystallization of $\mathrm{Bi}_{2} \mathrm{Fe}_{4} \mathrm{O}_{9}$ mullite particles on the other hand. Actually such situation explains why we observe a higher amount of mullite in the co-precipitated samples: the higher reactivity introduced in the system by this synthesis route improves the diffusion processes but it also enhances the crystallization of the mullite nuclei, so stopping the reaction even before than in the mixed-oxides processing. Also in the rapid heating experiments, we take the system to a high energetic state in which diffusion is favored, but even though the nucleation and crystallization of yet a trace amount of the mullite phase cannot be avoided.

\section{Conclusions}

The diffusion of $\mathrm{Bi}^{3+}$ ions into $\mathrm{Fe}_{2} \mathrm{O}_{3}$ governs the solid state synthesis of multiferroic $\mathrm{BiFeO}_{3}$ through a process which involves the formation of different secondary by-products. Initially a $\mathrm{Bi}_{25} \mathrm{FeO}_{39}(\mathrm{Bi}: \mathrm{Fe}=25: 1)$ sillenite-type phase forms at the shell whereas a $\mathrm{Bi}_{2} \mathrm{Fe}_{4} \mathrm{O}_{9}(1: 2)$ mullite-type phase is formed at the reaction/diffusion front towards the iron oxide core. In between both phases the perovskite-type (1:1) $\mathrm{BiFeO}_{3}$ develops as the diffusion proceeds and in a hypothetical end of reaction the secondary phases should entirely decompose to complete the formation of $\mathrm{BiFeO}_{3}$. However the real situation is pretty different. A competition is established between the diffusion process that tends to complete the formation of $\mathrm{BiFeO}_{3}$, and the 
crystallization of $\mathrm{Bi}_{2} \mathrm{Fe}_{4} \mathrm{O}_{9}$ mullite crystals, which showed up extremely stable and thus tend to block the reaction. Eventually a situation is achieved in which three phases coexist simultaneously and actually any change in the energy conditions fails to avoid the multiphase configuration.

\section{Acknowledgments}

This work has been conducted within the CICYT MAT 201016614 project. M.S. Bernardo also acknowledges the Spanish Ministry of Education for the financial support (FPU scholarship program).

\section{References}

1. Eerestein W, Mathur ND, Scott JF. Multiferroic and magnetic materials. Nature 2006;442:759-65.

2. Spaldin NA, Fiebig M. The renaissance of magnetoelectric multiferroics. Science 2005;309:391-2.

3. Catalan G, Scott JF. Physics and applications of bismuth ferrite. Adv Mater 2009;21:2463-85.

4. Kumar MM, Palkar VR, Srinivas K, Suryanarayana SV. Ferroelectricity in a pure $\mathrm{BiFeO}_{3}$ ceramic. Appl Phys Lett 2000;76:2764-6.

5. Wang J, Neaton JB, Zheng H, Nagarajan V, Ogale SB, Liu B, et al. Epitaxial $\mathrm{BiFeO}_{3}$ multiferroic thin film heterostructures. Science 2003;299:1719-22.

6. Ryu S, Kim JY, Shin YH, Park BG, Son JY, Jang HM. Enhanced magnetization and modulated orbital hybridization in epitaxially constrained $\mathrm{BiFeO}_{3}$ thin films with thombohedral symmetry. Chem Mater 2009;21:5050-7.

7. Achenbach GD, James WJ, Gerson R. Preparation of single-phase polycrystalline $\mathrm{BiFeO}_{3}$. J Am Ceram Soc 1967;50:437.

8. Carvalho TT, Tavares PB. Synthesis and thermodynamic stability of multiferroic $\mathrm{BiFeO}_{3}$. Mater Lett 2008;62:3984-6.

9. Selbach SM, Einarsrud MA, Grande T. On the thermodynamic stability of $\mathrm{BiFeO}_{3}$. Chem Mater 2009;21:169-73.

10. Lufaso MW, Vanderah TA, Pazos IM, Levin I, Roth RS, Nino JC, et al. Phase formation, crystal chemistry, and properties in the system $\mathrm{Bi}_{2} \mathrm{O}_{3}-\mathrm{Fe}_{2} \mathrm{O}_{3}-\mathrm{Nb}_{2} \mathrm{O}_{5}$. J Solid State Chem 2006;79:3900-10.

11. Rodrigues HO, Pires GFM, Almeida JS, Sancho EO, Ferreira AC, Silva MAS, et al. Study of the structural, dielectric and magnetic properties of $\mathrm{Bi}_{2} \mathrm{O}_{3}$ and $\mathrm{PbO}$ addition on $\mathrm{BiFeO}_{3}$ ceramic matrix. J Phys Chem Solids 2010;71:1329-36.

12. Bernardo MS, Jardiel T, Villegas M. Synthesis and microstructural evolution of $\mathrm{BiFeO}_{3}$ ceramics modified with $\mathrm{ZnO}$. Bol Soc Esp Ceram V 2010;49:47-52.

13. Wang YP, Zhou L, Zhang MF, Chen XY, Liu JM, Liu ZG. Room-temperature saturated ferroelectric polarization in $\mathrm{BiFeO}_{3}$ ceramics synthesized by rapid liquid phase sintering. Appl Phys Lett 2004;84:1731-3.

14. Chen J, Xing XR, Watson A, Wang W, Yu RB, Deng JX, et al. Rapid synthesis of multiferroic $\mathrm{BiFeO}_{3}$ single-crystalline nanostructures. Chem Mater 2007;19:3598-600.

15. Farhadi S, Rashidi N. Microwave-induced solid-state decomposition of the $\mathrm{Bi}\left[\mathrm{Fe}(\mathrm{CN})_{6}\right] \cdot 5 \mathrm{H}_{2} \mathrm{O}$ precursor: a novel route for the rapid and facile synthesis of pure and single-phase $\mathrm{BiFeO}_{3}$ nanopowder. $J$ Alloys Compd 2010;503:439-44.

16. Mazumder R, Chakravarty D, Bhattacharya D, Sen A. Spark plasma sintering of $\mathrm{BiFeO}_{3}$. Mater Res Bull 2009;44:555-9.

17. Freitas VF, Grande HLC, de Medeiros SN, Santos IA, Cotica LF, Coelho AA. Structural, microstructural and magnetic investigations in high-energy ball milled $\mathrm{BiFeO}_{3}$ and $\mathrm{Bi}_{0.95} \mathrm{Eu}_{0.05} \mathrm{FeO}_{3}$ powders. $J$ Alloys Compd 2008;461:48-52.

18. Liu Z, Qi Y, Lu C. High efficient ultraviolet photocatalytic activity of $\mathrm{BiFeO}_{3}$ nanoparticles synthesized by a chemical coprecipitation process. J Mater Sci Mater Electron 2010;21:380-4.

19. Park TJ, Sambasivan S, Fischer DA, Kumar S, Yoon WS, Misewich JA, et al. Electronic structure and chemistry of iron-based metal oxide nanostructured materials: a NEXAFS investigation of $\mathrm{BiFeO}_{3}$ $\mathrm{Bi}_{2} \mathrm{Fe}_{4} \mathrm{O}_{9}$, alpha- $\mathrm{Fe}_{2} \mathrm{O}_{3}$, gamma- $\mathrm{Fe}_{2} \mathrm{O}_{3}$, and $\mathrm{Fe} / \mathrm{Fe}_{3} \mathrm{O}_{4}$. J Phys Chem $\mathrm{C}$ 2008; 112:10359-69.

20. Popa M, Crespo D, Calderon-Moreno JM, Preda S, Fruth V. Synthesis and structural characterization of single-phase $\mathrm{BiFeO}_{3}$ powders from a polymeric precursor. J Am Ceram Soc 2007;90:2723-7.

21. Selbach SM, Tybell T, Einarsrud MA, Grande T. Size-dependent properties of multiferroic $\mathrm{BiFeO}_{3}$ nanoparticles. Chem Mater 2007;19:6478-84.

22. Han SH, Kim KS, Kim HG, Lee HG, Kang HW, Kim JS, et al. Il Cheon C Synthesis and characterization of multifermic $\mathrm{BiFeO}_{3}$ powders fabricated by hydrothermal method. Ceram Int 2010;36:1365-72.

23. Li S, Lin YH, Zhang BP, Wang Y, Nan CW. Controlled fabrication of $\mathrm{BiFeO}_{3}$ uniform microcrystals and their magnetic and photocatalytic behaviors. J Phys Chem C 2010;114:2903-8.

24. Zhang L, Cao XF, Ma YL, Chen XT, Xue ZL. Polymer-directed synthesis and magnetic property of nanoparticles-assembled $\mathrm{BiFeO}_{3}$ microrods. $J$ Solid State Chem 2010;183:1761-6.

25. Valant M, Axelsson AK, Alford N. Peculiarities of a solid-state synthesis of multiferroic polycrystalline $\mathrm{BiFeO}_{3}$. Chem Mater 2007;19:5431-6.

26. Morozov MI, Lomanova NA, Gusarov VV. Specific features of $\mathrm{BiFeO}_{3}$ formation in a mixture of bismuth(III) and iron(III) oxides. Russ $J$ Gen Chem 2003;73:1676-80.

27. Burriel F. Quimica Analitica Cualitativa. 16th ed. Cambridge, MA: International Thomson Publishing; 1998.

28. Peiteado M, Caballero AC, Makovec D. Diffusion and reactivity of

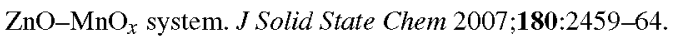

29. Maitre A, Francois M, Gachon JC. Experimental study of the $\mathrm{Bi}_{2} \mathrm{O}_{3}-\mathrm{Fe}_{2} \mathrm{O}_{3}$ pseudo-binary system. $J$ Phase Equilib Diff 2004;25:59-67.

30. Selbach SM, Einarsrud MA, Tybell T, Grande T. Synthesis of $\mathrm{BiFeO}_{3}$ by wet chemical methods. J Am Ceram Soc 2007;90:3430-4.

31. Makovec D, Kolar D, Trontelj M. Sintering and microstructural development of metal-oxide varistor ceramics. Mater Res Bull 1993;28:803-11.

32. Xu HH, Du Y, Zhou YC, Jin ZP. Determination of phase diagrams using the diffusion couple technique. Rare Metals 2006;25:427-30.

33. Peiteado M, Makovec D, Villegas M, Caballero AC. Influence of crystal structure on the $\mathrm{Co}^{\mathrm{II}}$ diffusion behavior in the $\mathrm{Zn}_{1-x} \mathrm{Co}_{x} \mathrm{O}$ system. $J$ Solid State Chem 2008;181:2456-61.

34. Homma T, Yamaguchi T. Reaction of multiphase ceramics - systems $\left(\mathrm{Zn}_{2} \mathrm{TiO}_{4}+\mathrm{TiO}_{2}\right)-\mathrm{ZnO}$ and -CaCO $3 . J$ Ceram Soc Jpn 1997;105:716-8.

35. Jardiel T, Caballero AC, Villegas M. Sintering kinetic of $\mathrm{Bi}_{4} \mathrm{Ti}_{3} \mathrm{O}_{12}$ based ceramics. Bol Soc Esp Ceram V 2006;45:202-6.

36. Greenwood NN, Earnshaw A. Chemistry of the Elements. 2nd ed. Oxford, UK: Pergamon Press; 1997.

37. Villegas M, Fernandez JF, Caballero AC, Samardija Z, Drazic G, Kosec M. Effects of $\mathrm{PbO}$ excess in $\mathrm{Pb}\left(\mathrm{Mg}_{1 / 3} \mathrm{Nb}_{2 / 3}\right) \mathrm{O}_{3}-\mathrm{PbTiO}_{3}$ ceramics: part II. Microstructure development. J Mater Res 1999;14:898-905.

38. Rossel M, Hohe HR, Leipner HS, Voltzke D, Abicht HP, Hollricher O, et al. Raman microscopic investigations of $\mathrm{BaTiO}_{3}$ precursors with core-shell structure. Anal Bioanal Chem 2004;380:157-62.

39. Liu G, Wang XH, Lin Y, Li LT, Nan CW. Growth kinetics of core-shellstructured grains and dielectric constant in rare-earth-doped $\mathrm{BaTiO}_{3}$ ceramics. J Appl Phys 2005;98:044105.

40. Tian ZB, Wang XH, Zhang YC, Fang J, Song TH, Hur KH, et al. Formation of core-shell structure in ultrafine-grained $\mathrm{BaTiO}_{3}$-based ceramics through nanodopant method. J Am Ceram Soc 2010;93:171-5. 